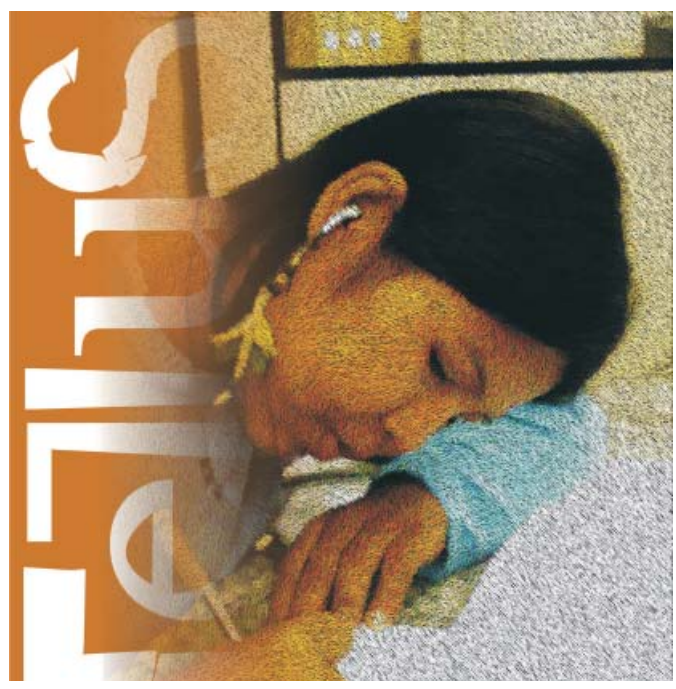

iconografia 



\section{Raposa Serra do Sol 2008, bastidores de filme etnográfico às vésperas da decisão do STF Raposa Serra do Sol 2008, bastidores de filme etnográfico às vésperas da decisão do STF}

\section{Barbara Arisi*}

A Raposa Serra do Sol fica em um dos pontos onde o Brasil se situa no hemisfério norte. É uma terra de savana e floresta homologada pelo presidente Lula em 2005 e registrada em 2008. Em março daquele ano, o governo enviara a Polícia Federal para retirar do local seis arrozeiros, mas estes responderam com violência. Dia 5 de maio, a mando de Paulo César Quartiero, maior arrozeiro da região, jagunços balearam dez indígenas enquanto estes construíam casas na aldeia ao lado da fazenda Depósito ${ }^{1}$. Estive na Raposa em junho, como voluntária, intérprete de espanhol/português e produtora de campo, para fazermos um documentário internacional sobre o conflito ${ }^{2}$. Nesse relato iconográfico e textual, registro os bastidores do filme etnográfico que fizemos às vésperas da decisão do STF a favor da demarcação em território contínuo.

\footnotetext{
${ }^{1}$ No dia seguinte, o ministro Tarso Genro, da Justiça, visitou a Raposa e comentou que a "a ação dos arrozeiros é "terrorista e ilegal'". Quartiero também é dono de duas fazendas na região e também, à época, era prefeito de Pacaraima, um dos três municípios onde está localizada a TI Raposa Serra do Sol. Quartiero foi preso após o tiroteio, ficou nove dias na cadeia e não perdeu o mandato. Atualmente, em 2011, ele é deputado federal pelo partido DEM de Roraima.

${ }^{2}$ A produtora chama-se Cipó e fez o documentário ‘ Raposa Serra do Sol: a luta decisiva', com ajuda de 5 mil euros da ONG Pueblos Hermanos, o objetivo era divulgar na Europa, em especial na Espanha e na América hispânica, a questão da disputa pela terra no Brasil. O filme ganhou prêmios de Melhor média metragem na III Mostra do Filme Etnográfico da UFAM, Manaus, e Melhor documentário no I Festival de Cine Solidario de Granada, Espanha. Nessa viagem, era a única brasileira do grupo e acompanhava os espanhóis Marta Caravantes (diretora), Lati Maraña (cameraman) e Maria Gestoso (produtora e técnica de áudio). Disponível em: <http://vimeo.com/9907289>.
}

* Doutoranda no Programa de Pós-Graduação em Antropologia Social (PPGAS/ UFSC), com estágio sanduíche no Institute of Social and Cultural Anthropology/

University of Oxford. Membro do Núcleo de Antropologia Visual e Estudos da Imagem (NAVI/UFSC) e do Núcleo de Estudos sobre Saberes e Saúde Indígena (NESSI/UFSC).

Pesquisadora do Instituto Nacional de Pesquisa Brasil Plural (INCT/IBP). E-mail: b.arisi@gmx.net

$$
\text { Tellus, ano 11, n. 20, p. 297-307, jan./jun. } 2011
$$


Na TI Raposa Serra do Sol, vivem 19 mil indígenas dos povos Macuxi, Tauarepang, Patamona, Ingarikó e Wapichana e por onde circulam também Yanomami; 300 deles são professores e 403 Agentes Indígenas de Saúde (AIS). A área tem 1,74 milhão de hectares, dos quais 17 mil, na ocasião do documentário, estavam ocupados por arrozeiros. Na época, a questão inquietava povos indígenas e indigenistas de todo país, pois, se o STF fosse contrário à homologação da área em território contínuo, seria aberto um precedente jurídico, uma vez que seria a primeira vez na história do Brasil que se voltaria atrás em uma homologação de terra indígena no país3.

Para documentar o conflito, nós tínhamos uma autorização assinada por Márcio Meira, presidente da Fundação Nacional do Índio (FUNAI). Mesmo assim, o administrador da FUNAI em Boa Vista, Gonçalo Teixeira, tentou de vários modos impedir nossa entrada. Depois de três dias, o Conselho Indígena de Roraima (CIR), associação que reúne lideranças indígenas da área, resolveu nos dar mais uma autorização, nosso salvo-conduto para visitar as comunidades. Finalmente, após rodar $170 \mathrm{~km}$ pelo asfalto de Boa Vista até a TI São Marcos e mais $30 \mathrm{~km}$ por terra, chegamos à ponte que a liga ao território demarcado como TI Raposa Serra do Sol, sobre o rio Surumu, e onde há uma enorme bandeira brasileira. Do outro lado, fica a Comunidade do Barro, antes chamada Vila Surumu, onde uma cancha de esportes cercada por faixas indicava zona de conflito. 'Roraima é Brasil', 'Polícia Federal não, Exército, sim' diziam as faixas dos colonos contra a homologação em território contínuo. Eles defendiam que a terra fosse registrada em ilhas, ou seja, em trechos descontínuos.

\footnotetext{
${ }^{3} \mathrm{O}$ procurador-geral da República, Antônio Fernando Souza, havia recomendado a retirada imediata dos ocupantes não-indígenas, mas o Supremo Tribunal Federal (STF) suspendeu as atividades da Fundação Nacional do Índio (FUNAI) e da Polícia Federal (PF), chamada de operação Upatakon III que começara em março.
} 


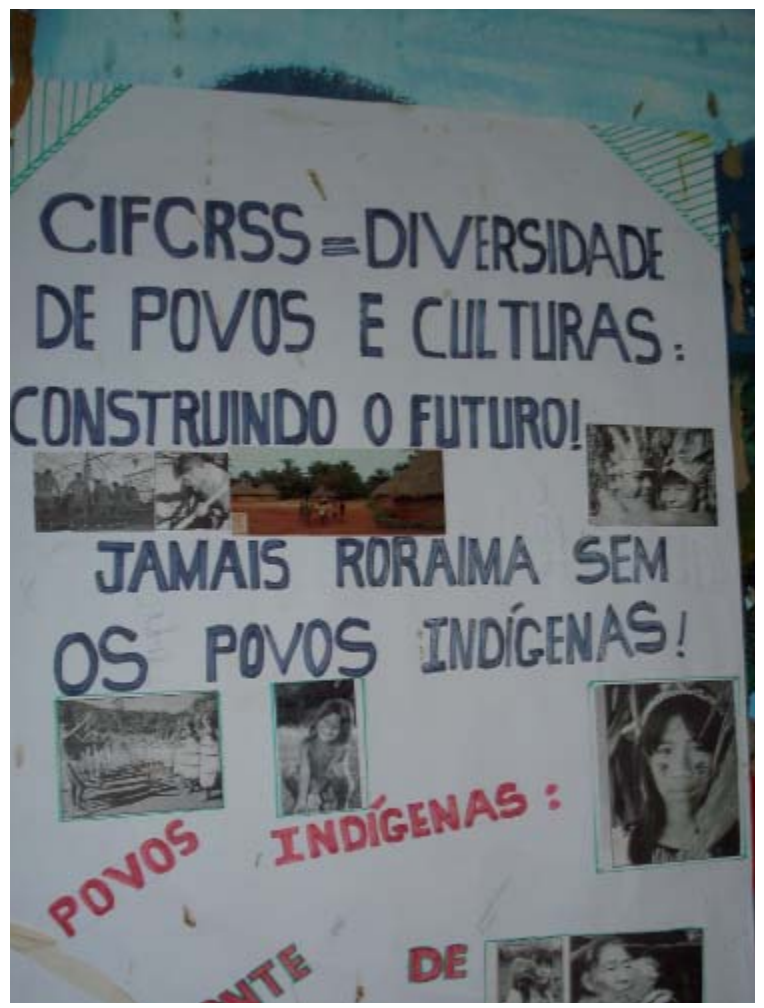

Foto 1 - Cartaz no Centro Indígena de Formação e Cultura Raposa Serra do Sol.

Ali perto, numa cozinha coberta de palha e sem paredes, encontramos um grupo de índios Macuxi e gravamos entrevistas sobre o conflito armado que dois deles presenciaram. Dia 5 de maio de 2008, entre 9h30min e 10h, Santinha da Silva e seus filhos ajudavam a armar casas para iniciar comunidade nova perto da estrada de terra RR-171 que leva a Uiramutã. Chegaram uns homens de moto, com gorros de lã negra, e ficaram uns 15 minutos por ali, fazendo barulho com o motor, saíram e voltaram logo depois, deram então um sinal e vieram todos já encapuzados: os dois motoqueiros e outros dez que estavam de apoio. Jogaram uma bomba, depois começaram a atirar com armas de cano longo; um índio caiu, e outra bomba. Começaram a chutar e bater com paus, os mais próximos foram feridos por estilhaços de chumbo. Uma picape da Polícia Federal foi buscar os feridos para levá-los a um hospital. Os índios haviam filmado a agressão e mandaram as imagens para o Conselho Indígena de Roraima (CIR) e elas correram mundo veiculadas no You Tube ${ }^{4}$

\footnotetext{
${ }^{4}$ Para assistir uma das postagens do video, acesse http://www.youtube.com/watch?v= 6wzpe1ML0ts.
} 
Do outro lado da cancha de esportes, ninguém queria conversa com a gente. Desistimos de tentar entrevistá-los e fomos conhecer a antiga escola dos missionários, atual centro de formação agrícola e de lideranças, localizado a 20 minutos de carro da Vila do Barro. Deparamos com um grupo de casas meio queimadas, paredes derrubadas, um carro incendiado abandonado na entrada. O responsável pelo centro de ensino é um ex-aluno e chama-se Anselmo Dionísio Filho, 35. Ao todo, 50 estudantes de diferentes povos Yekuana, Wapichana, Ingarikó, Wai-wai e Macuxi - estudaram ali durante 4 anos. Nas aulas, se aprendem técnicas de agroecologia, como aumentar a produtividade da agricultura familiar, como reaproveitar resíduos animais e sobre os três ecossistemas predominantes de Roraima: serra, lavrado/savana e floresta; e também como ser "liderança", escrever projetos, organizar reuniões comunitárias, como se relacionar com instituições não-indígenas e lidar com o mundo dos brancos. Anselmo sentou-se no meio dos escombros, onde gravamos.

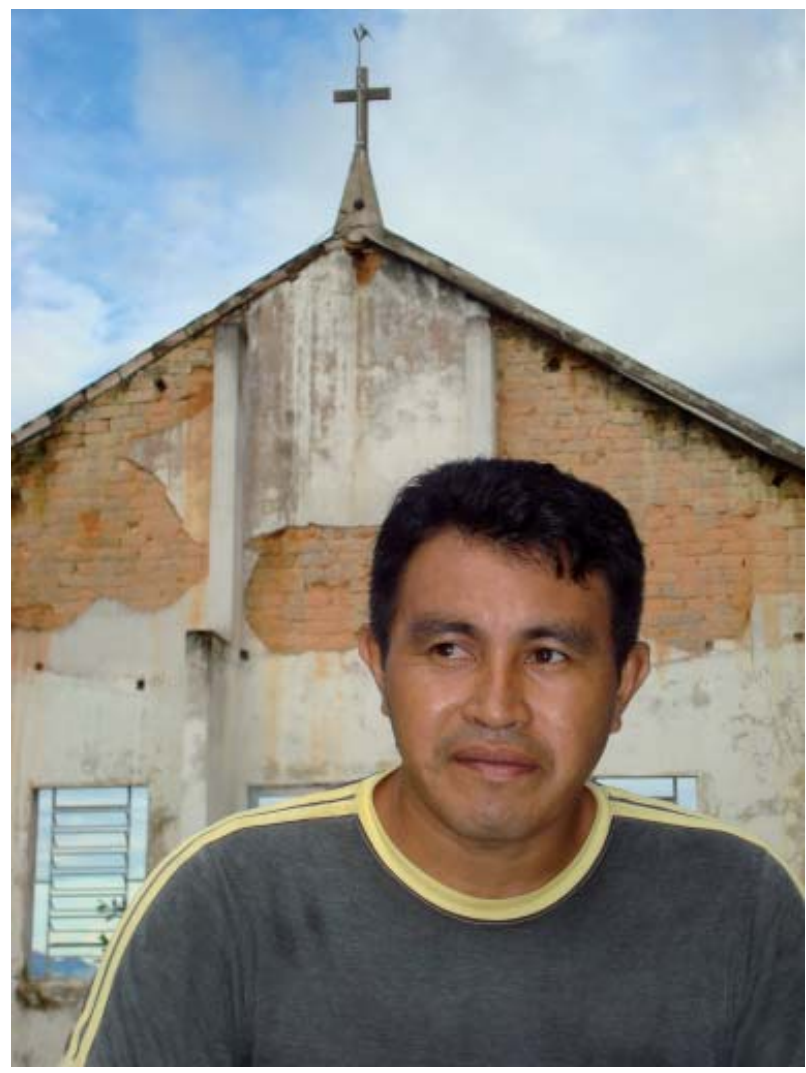

Foto 2 - Anselmo Dionísio Filho relembra o dia em que incendiaram o Centro. 
Atearam fogo na nossa escola em 17 de setembro de 2005. Chegaram uns 150, 200 homens armados, a mando do agricultor Paulo César Quartiero, feriram 10 pessoas a bala, dois eram nossos alunos adolescentes, depois atearam fogo em tudo, na igreja, na unidade hospitalar, nos dormitórios, nas salas de aula, queimaram livros, espancaram um professor que estava aqui dando um curso pelo SENAI. Eu mandei minha mulher fugir com nosso filho, saí correndo pro mato, porque senão teriam me matado. Em 2004, uns missionários haviam sido sequestrados ali também. Eu acredito que os dois episódios foram tentativas para dificultar a homologação da terra indígena. (Anselmo).

No rumo de Uiramutã, uma das pontes sobre um igarapé foi queimada no mês de maio, parte das atividades dos arrozeiros às quais o ministro da Justiça Tarso Genro tachou de "terroristas". Adiante, no lado direito da estrada, há uma cerca que antes servia para delimitar a fazenda de Quartiero até a margem do rio Surumu, cujas águas eram aproveitadas para irrigação ilegal de sua lavoura, pois ele não possuía licença ambiental do Instituto Brasileiro do Meio Ambiente e dos Recursos Naturais (Ibama). Paramos na comunidade Dez Irmãos, onde três barracas armadas sob lona azul estendidas sobre estacas marcam o local do último tiroteio e lembram que foram dez os índios feridos na ocasião. Elizário André, 15, é um dos dois jovens entrevistados que nos contou como correu de bala naquele 5 de maio e ficou com vários estilhaços de chumbo embaixo do couro cabeludo, na perna direita, nas costas e atrás da orelha. "Sofremos ameaças sempre, até mesmo por parentes indígenas que foram comprados pela bebida dos fazendeiros para ficar do lado deles. Aqui só tem justiça para quem tem dinheiro, nós somos abandonados; para nós a justiça é rápida, para os ricos é lenta. O [Paulo César] Quartiero foi preso num dia e solto logo depois", reclama Telson Lima Macuxi, outro sobrevivente.

Dirigimos à noite e, às $23 \mathrm{~h}$, chegamos a Uiramutã, município criado em 1996 pelo estado de Roraima após o reconhecimento da terra indígena, o que serviu para acirrar as tensões provocadas pela ocupação e grilagem. Passamos pelo quartel do Exército, cruzamos mais um igarapé e, por fim, paramos ao lado da casa com paredes de pau-a-pique e telhado de palha de nosso anfitrião, o cacique/tuxaua Orlando Silva, 70 anos. Na cozinha de chão batido, ele e sua esposa Luiza nos serviram café e ele contou: "Essa terra foi demarcada pelo marechal Rondon em 1927, tenho uma placa desse tempo, de cobre, que o Rondon deixou para mostrar que essa terra era nossa e fica dentro do território brasileiro. Minha avó trabalhou de cozinheira para a turma que veio com Rondon colocar esses marcos de fronteira com a Guiana e, do lado dos parentes Ingarikó, com a Venezuela”. "Toda a vida guarnecemos as fronteiras do Brasil", responde ele a comentários comuns na mídia brasileira de que os índios seriam uma ameaça à soberania nacional, tal como o que recentemente havia sido feito pelo general Augusto Heleno, comandante militar da Amazônia que depois teve de se retratar e pedir desculpas públicas. 
A paisagem ao redor de Uiramutã é formada por morros cobertos de poucas árvores retorcidas de savana e fios altos de capim verde limão que, com o vento, se movem incessantes como um mar onde parecem flutuar enormes pedras negras. No dia seguinte, enquanto tocava uma pedra, Orlando nos contou que esta é um ovo transformado em rocha pelo herói mítico Macunaíma. Filmamos um rio próximo da comunidade da Lage, cujas águas têm forte correnteza, um dos poucos não assoreados pelo garimpo.

Na escola, Leonardo, filho de Orlando e diretor da escola, realizava uma reunião com os pais dos alunos. $\mathrm{O}$ diretor sabe que os brancos que vivem longe perguntam se os Macuxi seguem sendo índios quando usam roupas de branco, comem carne de gado e compram arroz, por isso, já começamos nossa gravação com ele se explicando. "Ser índio é querer viver bem, ter saúde, se alimentar, brincar, poder ensinar nossos filhos como surgiu o mundo, nossas festas e danças, fazer caxiri [bebida fermentada tradicional] e aproveitar também o que as outras culturas têm de bom, como o futebol e as roupas."

Quando o avô de Orlando tinha uns 50 anos, chegaram os não-índios, assentaram casa perto da aldeia, trouxeram gado e os tratavam de 'compadre'. Seu avô pensava que logo os não-indígenas iriam embora. Orlando narrou uma biografia que junto conta a história do lugar:

'Os do gado' foram tomando conta dos rios e da terra e, depois, chegaram 'os garimpeiros' destruindo os igarapés e os rios, assoreando com suas máquinas de drenagem e poluindo de mercúrio. Os índios ficaram perdidos, se afundaram na bebida, trabalhavam até de graça a troco de cachaça, a gente pegava ouro, diamante e não sabia o preço, ficávamos sempre devendo pros patrões. Meu pai era um desses índios perdidos. Certo dia um compadre perguntou pro meu pai:"Quanto você quer pelo menino? Preciso de ajuda para cuidar da minha mulher doente". Eu tinha oito anos naquela época, e meu pai recebeu facão, sal e sabão. Eu fui vendido, mas era criança e não sabia, fiquei fora de minha comunidade até os 16 anos. Quando quis ir embora, a mulher falou que eu ainda não tinha acabado de pagar a dívida do meu pai, mas eu fui mesmo assim. (Orlando Macuxi)

Ao chegar a sua comunidade, Orlando contou que encontrou quase todo mundo escravo no garimpo, trabalhando um mês em troca de uma rede de dormir, sem plantar feijão e roça. As mulheres reclamavam que os maridos iam para os rios buscar ouro e diamante e não voltavam mais. Orlando tocava acordeão e animava os bailes de garimpeiros quando seu pai o colocou para ser cacique com apoio dos garimpeiros.

Na primeira reunião comunitária, Orlando surpreendeu ao exigir que todos os pais de família viessem sóbrios. Cancelou duas vezes os encontros porque algum índio estava bêbado. Decretou o fim das bebidas alcoólicas e das festas com brancos e depois ajudou a correr com os garimpeiros. "Eles só 
traziam poluição, cachaça e malária; a gente foi tirando o garimpo sem matar ninguém, o Exército e a Polícia Militar eram contra a gente, nem se falava da Polícia Federal, e a FUNAI era fraca".

Antes dos garimpeiros, os índios já haviam sido pressionados pela empresa colonial que os caçava para serem escravos em Belém do Pará. No final do século 18, chegou também a pecuária. O padre e historiador da diocese de Boa Vista, Vanthuy Neto, afirmava que "a segunda empresa colonial começou pelas patas do gado. Criaram nos indígenas novas necessidades de roupa, ferramentas de metal e alimentos". Depois, entre 1988 e 1992, houve a invasão do garimpo, quando cerca de 40 mil homens vieram procurar ouro ali e também em terras dos Yanomami. O impacto foi tamanho e tão repentino que provocou um forte movimento indígena. Assim o governo federal se viu obrigado a reagir e, em 1991, a TI Yanomami estava homologada.

No final do século 20, chegou o agronegócio na região da Raposa. Imagens do Instituto de Pesquisas Aeroespaciais (INPA) mostram o crescimento dos arrozais, principalmente depois de 1996 com ocupação de áreas de preservação permanente (APPs), aterramento de rios, desmatamento de mata ciliar e valas de irrigação para lavouras. Apenas para exemplificar, em maio de 2008, o Ibama aplicou quatro multas e embargou as atividades econômicas da fazenda Depósito, de Quartiero. Em janeiro de 2005, o órgão ambiental já havia multado as fazendas Depósito e Providência, ambas de Quartiero, e a fazenda Canadá, do também gaúcho Agenor Faccio. Além de pagar multa, os arrozeiros deveriam fazer reposição ambiental pelos danos provocados. Para nosso documentário, entrevistamos também a superintendente do Ibama em Roraima, Nilva Baraúna, que nos informou que, no período entre 2005 e 2007, muitas propriedades praticamente dobraram de tamanho. "Os agrotóxicos usados nas lavouras são lavados pela cheia do rio Surumu, e os produtos químicos descem até o rio Branco e chegam à capital Boa Vista." O agronegócio na Raposa Serra do Sol é ilegal, pois nunca foi licenciado no Ibama. 


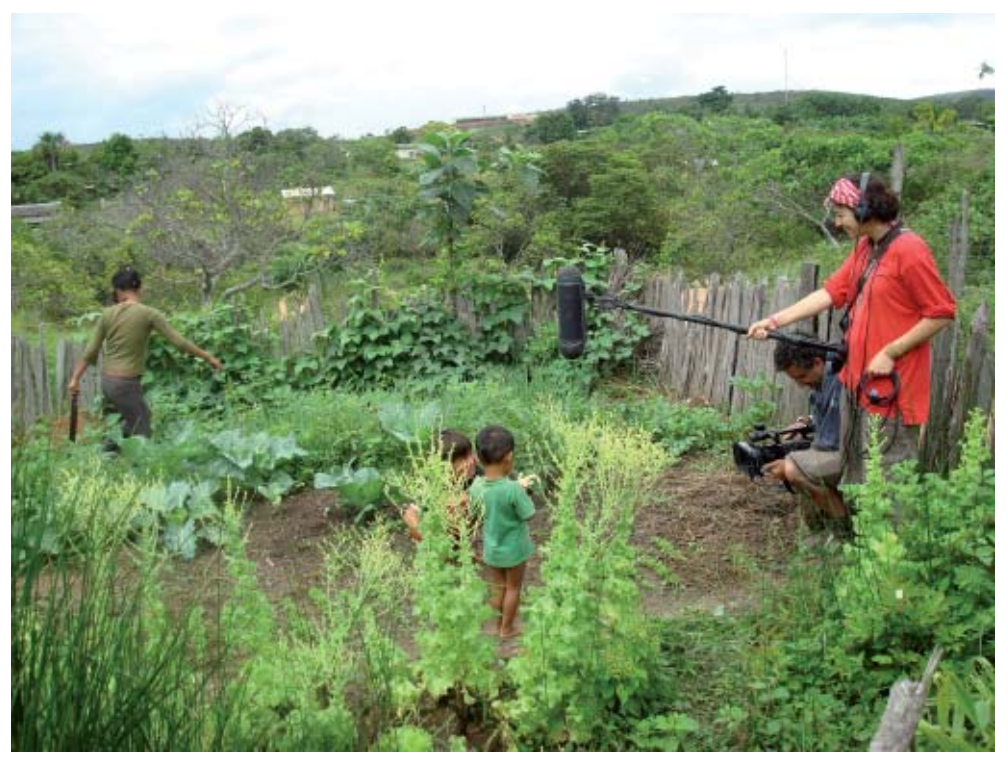

Foto 3 - Equipe espanhola filma Doralice, Wawim e Pixaná, filhos e neto do tuxaua Orlando.

Outras duas importantes entrevistas em Boa Vista fizemos com Davi Kopenawa Yanomami, coordenador da Hutukara Associação Yanomami, e com Carlos Alberto 'Beto' Ricardo, coordenador do Instituto Socioambiental. Beto Ricardo nos resumiu a situação dos povos indígenas frente aos projetos de crescimento do governo Lula, gerados pelo Plano de Aceleração do Crescimento (PAC):

Creio que é possível o governo brasileiro proteger a megadiversidade socioambiental do país sem colocar em risco as áreas indígenas. Estamos em época de euforia econômica, o governo Lula é desenvolvimentista, e os índios estão sendo pressionados pela expansão da fronteira agrícola. $\mathrm{O}$ Brasil é o único país do mundo que tem nome de árvore, mas já começou fazendo com que os índios cortassem o pau-brasil. Temos uma tradição predatória em nosso país que deve e pode mudar, precisamos de outros modelos de desenvolvimento. Se a decisão do Supremo for desfavorável aos indígenas da Raposa, será um grave precedente para todas Terras Indígenas do Brasil e para o meio ambiente. (Carlos Alberto Ricardo).

Orlando Macuxi estava com esperança de que os anos de luta para recuperar a terra e a dignidade de seus avós estivessem chegando ao último capítulo. O cacique da comunidade de Uiramutã, cuja sede municipal ficou de fora da área da TI Raposa Serra do Sol, esperava em 2008 uma decisão favorável do Supremo Tribunal Federal. "Tenho certeza de que a terra pertence a meus filhos e netos". 


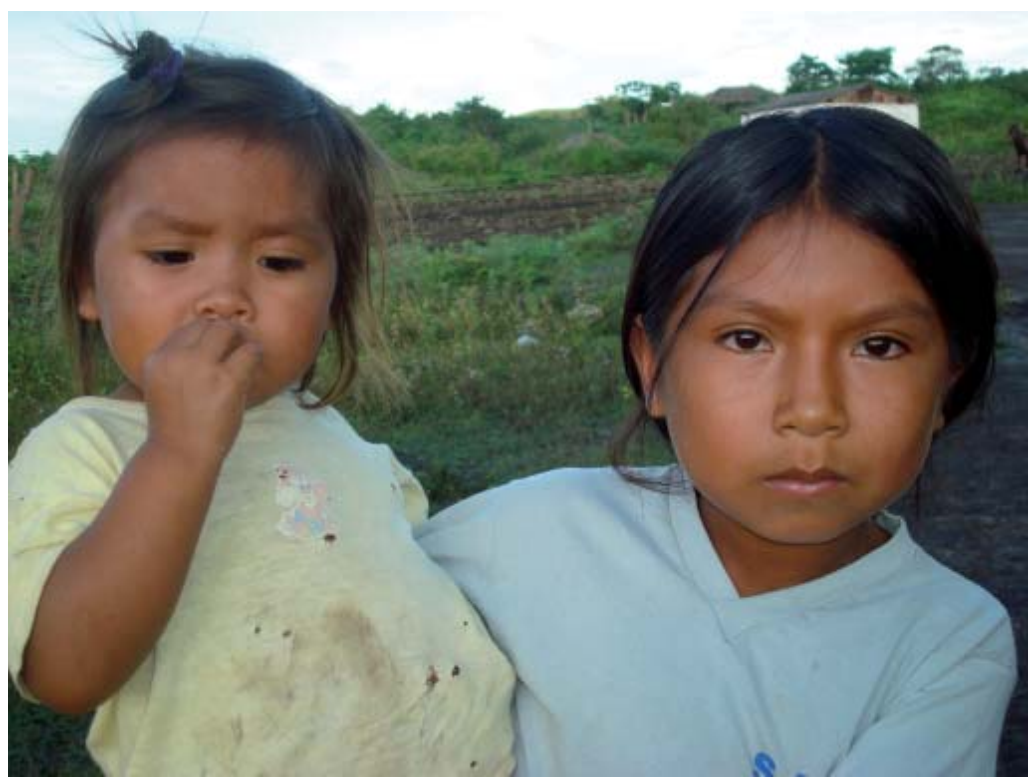

Foto 4 - Meninas Macuxi na comunidade Lage.

Em Boa Vista, fizemos imagens dos arrozais na beira das estradas. Em uma rápida enquete de rua, perguntamos: "Você é contra ou a favor da demarcação contínua da Raposa? E por quê?" Entre 35 entrevistados na porta de um supermercado no centro da cidade, apenas dois eram a favor dos índios. Por fim, gravamos com Gercimar Morais, índio Macuxi e coordenador do Projeto Integrado de Proteção às Populações Indígenas da Amazônia Legal (PPTAL)5. Ele contou um dos mitos de origem de seu povo. Os velhos Macuxi contavam que, na Raposa Serra do Sol, havia uma árvore imensa e frondosa que dava todo tipo de frutos que hoje existem pelo mundo. Os dois irmãos demiurgos Anike e Inskiran, depois de cavarem os rios da região, resolveram derrubar a árvore. Bateram, cortaram, serraram e, por fim, colocaram abaixo o colosso; quando esta caiu fez um estrondo enorme e espalhou todos os tipos de frutas, hortaliças e legumes pela terra. O toco cortado é o Monte Roraima. A partir de então, nunca mais uma mesma árvore deu tipos diferentes de fruta, as árvores viraram monocultura. Era quase uma metáfora do conflito travado no tempo presente.

\footnotetext{
${ }^{5}$ O PPTAL é um Projeto Integrado de Proteção às Populações e Terras Indígenas da Amazônia Legal (PPTAL), faz parte do Programa Piloto para a Conservação das Florestas Tropicais do Brasil (PPG7), criado para proteger as florestas tropicais e conservar a biodiversidade, reduzindo as emissões de carbono e promovendo um maior conhecimento das atividades sustentáveis da Floresta Tropical.
} 
As narrativas aqui apresentadas foram colhidas em 2008, nos bastidores de um filme etnográfico realizado às vésperas da decisão do STF. Essa luta pela terra terminou com um surpreendente final feliz para os povos indígenas da Raposa Serra do Sol e do Brasil. A professora Alcida Ramos resume bem as transformações pelas quais os povos da Raposa tiveram de passar para conseguir vencer essa longa batalha judicial:

Com o passar das décadas, a realidade interétnica ainda é desigual e conflituosa, mas o papel político dos índios tem mudado substancialmente. Para dar um exemplo, lembro-me dos Macuxi de Roraima quando comecei a fazer minha pesquisa de campo com os Yanomami no fim da década de 1960. Eram humildes varredores das ruas de Boa Vista que mal ousavam levantar os olhos do chão e pareciam querer fazer-se invisíveis para aquele mundo hostil que ao mesmo tempo os envolvia e os rechaçava acintosamente. Viviam então o lado mais sombrio da fricção interétnica, relegados à absoluta marginalidade social, cultural e econômica. Quarenta anos depois, os mesmos Macuxi, aliados aos Wapichana e outros povos do lavrado de Roraima, eram os protagonistas de uma das mais célebres batalhas judiciais dos tempos modernos ao defender, em igualdade de condições, os seus direitos territoriais contra empresários da agroindústria que ocupavam ilegalmente suas terras. Os esforços dos advogados indígenas foram cruciais para que os habitantes tradicionais da Raposa-Serra do Sol saíssem vitoriosos na decisão do Supremo Tribunal Federal, que confirmou a validade de sua Terra Indígena em forma contínua e afastou invasores arrogantes e belicosos (Miras et alii 2009). A educação formal transformou aquela invisibilidade macuxi numa demonstração exemplar de agencialidade e força política. (Ramos, 2010).

Em 2011, a mídia nacional6 continua uma campanha preconceituosa com a qual tenta criar uma imagem dos índios como incapazes e vagabundos que não cuidam de sua terra. Para os povos da Raposa Serra do Sol, a batalha da demarcação está ganha, mas ainda há muito a fazer. Eles mostram que são mais do que capazes e muito bem preparados. Prova disso foi quando, pela primeira vez na história do Brasil, um indígena subiu na tribuna do Supremo Tribunal Federal para fazer uma sustentação oral. A façanha coube a Joênia Batista de Carvalho Wapichana, uma advogada mulher indígena que, com o rosto pintado de urucum, se dirigiu aos onze juízes do STF para fazer ouvir a voz de 19 mil índios da TI, gente como Orlando Macuxi e Anselmo Dionísio Filho. Após 30 anos de conflito, finalmente a TI foi registrada em território contínuo, embora o STF tenha imposto 19 condições que são um retrocesso em relação a conquistas antigas do movimento indígena.

\footnotetext{
${ }^{6}$ Por exemplo, revista Veja de 30/5/2011 ou reportagens nas TV e rádio Bandeirantes veiculadas na segunda metade de julho de 2011.
} 


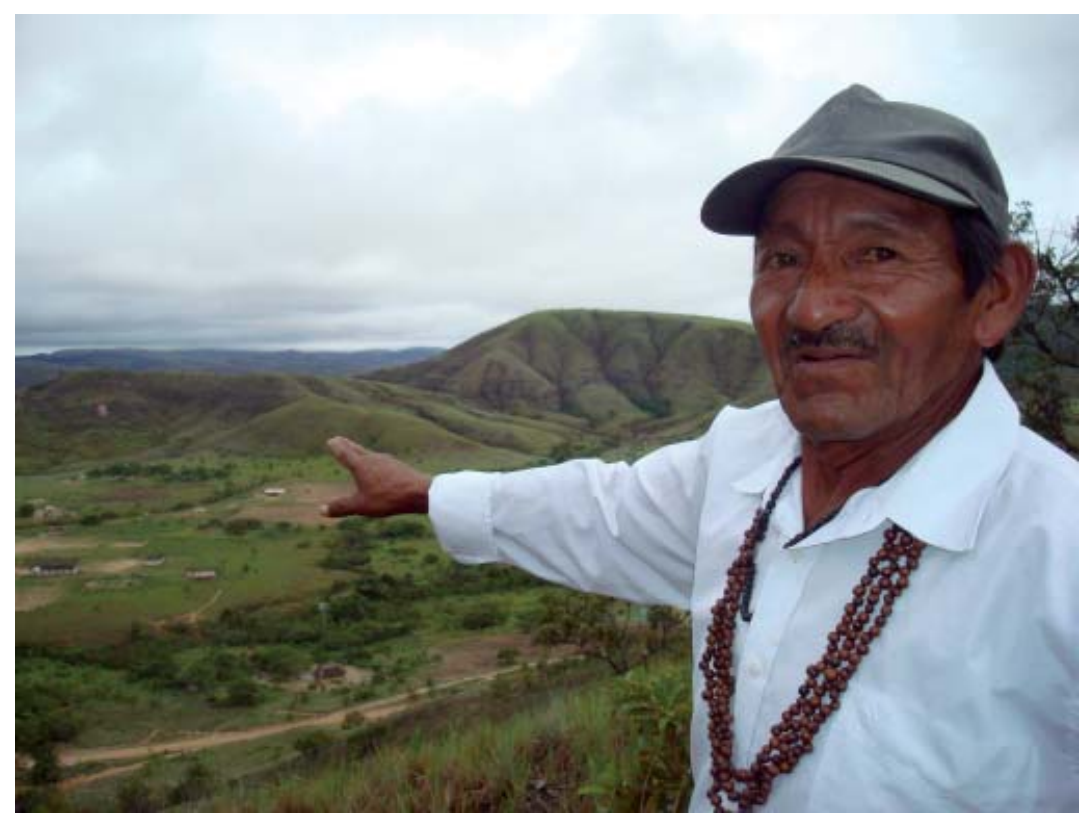

Foto 5 - Cacique Orlando Macuxi mostra sua comunidade Uiramutã.

\section{Referências}

RAMOS, Alcida. Revisitando a etnologia à brasileira. In: MARTINS, Carlos Benedito (Org.). Horizontes das Ciências Sociais: Antropologia. São Paulo: Vozes/ANPOCS, 2010.

Recebido em 23 de novembro de 2010

Aprovado para publicação em 4 de janeiro de 2011 
